\title{
Pesquisa levantamento para análise do modelo de compras conjuntas adotado em arranjos produtivos locais de Minas Gerais
}

\author{
Pedro Henrique Athanasio Delalibera ${ }^{\mathrm{a} *}$, Renato Silva Lima ${ }^{\mathrm{b}}$, João Batista Turrionic \\ a*pedrodelalibera@unifei.edu.br, UNIFEl, Brasil \\ ${ }^{\mathrm{b}}$ rslima@unifei.edu.br, UNIFEl, Brasil \\ ‘4058@unifei.edu.br, UNIFEl, Brasil
}

\begin{abstract}
Resumo
Considerando que em muitas empresas o valor da compra de suprimentos é bastante significativo, o bom gerenciamento da função compras e do relacionamento com fornecedores pode assegurar maior competitividade aos seus produtos e serviços, trazendo melhores resultados aos acionistas. Todavia, esse tema ainda parece ser um privilégio das grandes organizações. Por limitações internas e externas, as pequenas e médias empresas estão à margem da gestão de relacionamento com fornecedores e da correta gestão de compras. Muitas pequenas e médias empresas, com intuito de superar as várias limitações gerenciais ou tecnológicas, dentre elas as limitações relacionadas ao gerenciamento da cadeia de suprimentos, puderam se organizar em Arranjos Produtivos Locais (APLs), fundamentalmente atuantes no setor industrial. Esse tipo de arranjo é formado por empresas pertencentes a um setor específico, onde há concorrência, mas também há práticas de cooperação. Dentre essas práticas destaca-se o compartilhamento e união dos lotes de compras, através do processo de compras conjuntas. Nesse contexto, o objetivo do trabalho é analisar os modelos de compras conjuntas adotados pelos Arranjos Produtivos Locais industriais concentradas no estado de Minas Gerais. Para tanto foi estruturada e aplicada uma pesquisa levantamento junto às empresas pertencentes aos APLs industriais mineiros. Com os resultados obtidos pôde-se concluir que, de modo geral, as compras conjuntas em Arranjos Produtivos Locais Mineiros são incipientes e não sistemáticas.
\end{abstract}

Palavras-chave

Compras conjuntas. Compras em grupo. Pequenas e médias empresas (PMEs). Cooperação entre empresas. Arranjos produtivos locais.

\section{Introdução}

Compras em grupo (compras cooperativas, compras colaborativas e compras conjuntas), processo de cooperação entre duas ou mais organizações em uma ou mais etapas de um processo de compras (Schotanus \& Telgen, 2007) têm recebido pouca atenção da literatura, apesar do longo histórico de sua prática nas organizações e nos estudos acadêmicos (Essig, 2000; Tella \& Virolainen, 2005; Schotanus \& Telgen, 2007). Essa falta de atenção dos pesquisadores é injustificada, pois muitas organizações realizam ou planejam realizar compras conjuntas (Essig, 2000; Tella \& Virolainen, 2005).

0 bom gerenciamento da função compras e do relacionamento com fornecedores podem levar a melhores retornos para os acionistas. Em muitas empresas, o valor de compra de materiais e componentes pode representar de 50\% a $80 \%$ do custo total da mercadoria vendida (Gelderman \& Van Weele, 2000).

Apesar da evolução e do aumento da importância do tema gerenciamento do relacionamento com fornecedores ao longo do tempo, o estudo e a prática parecem estar bastante restritos às grandes empresas, a despeito da importância das pequenas e médias empresas, apontadas como elementos essenciais para a prosperidade econômica em vários países (Mcadam \& Armstrong, 2001; Laforet, 2009; Toledo et al., 2008; Soderquist et al., 1997). 
Uma das soluções encontradas para superação das várias limitações gerenciais ou tecnológicas enfrentadas pelas pequenas e médias empresas, dentre elas as relacionadas ao gerenciamento da cadeia de suprimentos, foi a formação de arranjos cooperativos entre empresas, os Arranjos Produtivos Locais, atuantes no setor industrial.

Ao considerar a definição de arranjos entre empresas de Porter (1998) como empresas interconectadas, pertencentes a um setor específico, onde há concorrência mas também há práticas de cooperação, a colaboração em cadeias de suprimentos com vistas à melhoria do gerenciamento da função compras e do relacionamento com fornecedores através da prática das compras conjuntas pode ser um caminho natural na evolução colaborativa nos arranjos interorganizacionais.

Nesse contexto é interessante verificar se existe e como se dá o processo de cooperação em compras nas empresas dos Arranjos Produtivos Locais, ou seja, qual é o modelo de compras colaborativas adotado nesse tipo de arranjo entre empresas. Para cumprir esse objetivo, este trabalho apresenta uma pesquisa levantamento aplicada às empresas pertencentes aos Arranjos Produtivos Locais (APL) industriais do estado de Minas Gerais.

O trabalho está estruturado da seguinte maneira: após essa rápida introdução, apresenta-se a fundamentação teórica sobre os temas função compras (seção 2.1), Arranjos Produtivos Locais (seção 2.2), compras conjuntas (seção 2.3) e a lei brasileira em relação às compras conjuntas (seção 2.4). A seção 3 traz toda a descrição da pesquisa e das análises efetuadas, seguida das conclusões, na seção 4, e das referências bibliográficas.

\section{Fundamentação teórica}

\subsection{Função compras}

A natureza estratégica da função compras é debatida na literatura acadêmica há vários anos. Exemplo disso são os estudos dos portfólios de compra de Kraljic (1983). Portanto, há algumas décadas, pesquisadores argumentam que a aquisição tem um papel cada vez mais central na gestão dos recursos da empresa, aumentado o status quo da função compras (Cousins et al., 2006).

As habilidades da função compras também mudaram consideravelmente durante os anos. 0 papel do comprador mudou da concentração predominante no preço, entrega e qualidade para o foco também na gestão estratégica de longo prazo, acordos complexos entre as partes interessadas internas e fornecedores (Faes et al., 2001).

Alguns autores apontam que existem diferenças significativas na função compras entre as empresas de pequeno porte e as grandes empresas, sobretudo nos aspectos relacionados à escolha dos fornecedores, na prioridade e destino de recursos e esforços para desenvolvimento dessa função.

Para Morrissey \& Pittaway (2004), as PMEs possuem grande dificuldade no suprimento de produtos e serviços, pois a globalização trouxe consigo o aumento da pressão para redução contínua dos preços num contexto de melhoria de qualidade e de serviço. Além disso, para muitas empresas, as despesas com bens e serviços representam uma elevada percentagem do volume de negócios e é influente para obtenção dos objetivos empresariais. No entanto, como sugerem Morrissey \& Pittaway (2004), apesar da pressão por menores preços e da influência dos suprimentos nos resultados da empresa, o gestor da pequena empresa parece adotar outros critérios além dos fatores financeiros. Aspectos comportamentais, considerando-se fatores sociais, também são levados em conta na decisão de compra, igualando-se ou mesmo obtendo um peso maior na decisão, se comparados aos fatores financeiros, agregadores de valor e que contribuem para a rentabilidade global das menores empresas.

Para Aun (2005), pode-se segmentar o relacionamento com os fornecedores em três níveis. 0 primeiro deles é o passivo, caracterizado por falta de planejamento e orientação estratégica, pouca comunicação e seleção de fornecedores baseada em preço e disponibilidade. 0 segundo nível da evolução dos relacionamentos é o de transição, no qual passa a existir uma direção estratégica, sendo que o setor de compras estabelece vínculos com outros setores e o desempenho é monitorado. Por fim, no nível proativo, a organização passa a considerar os fornecedores como componentes do sucesso, a gestão de compras passa a ser integrada aos departamentos, com o desempenho calculado de acordo com a contribuição do resultado.

Murad (2009), em uma pesquisa realizada no Arranjo Produtivo Local da indústria eletrônica localizado em Santa Rita do Sapucaí, MG, concluiu que as pequenas empresas do APL estudadas relacionavam-se de forma tradicional com seus fornecedores, ou seja, na forma passiva de Aun (2005), caracterizada pela falta de planejamento e orientação estratégica, pouca comunicação e seleção de fornecedores baseada em preço e disponibilidade. Murad (2009) ainda menciona que as médias empresas pesquisadas nesse APL apresentaram um relacionamento com os principais fornecedores de segundo nível, ou seja, do tipo de transição, apontado 
por Aun (2005), no qual o setor de compras estabelece vínculos com outros setores e o desempenho é monitorado pelas medidas de qualidade e eficiências logísticas.

\subsection{Arranjos Produtivos Locais (APL) industriais de pequenas e médias empresas}

Para superação das várias limitações gerenciais ou tecnológicas enfrentadas, as pequenas e médias empresas podem formar arranjos cooperativos entre empresas, os APLs.

Noronha \& Turchi (2005) afirmam que o termo APL tem sido usado como designação genérica para qualquer arranjo produtivo de certa especialidade em uma determinada localidade, independentemente dos números da produção, da quantidade de empresas e da antiguidade ou do grau de articulação entre os integrantes do arranjo produtivo. Esses autores também destacam a forma com que o APL se contrapõe às definições atribuídas a cluster, cuja ênfase identificada pelos estudos está não só na presença de especialização mas especialmente na concentração de boa parte da cadeia produtiva em uma determinada região.

Porter (1999) argumentou que para que haja um cluster é necessário que se tenha:

- Uma grande empresa ou concentração de empresas semelhantes (verticalidade);

- Setores que utilizam serviços ou produtos comuns ou oferecem serviços e produtos complementares (horizontalidade);

- Instituições que oferecem qualificações especializadas, tecnologias, informação, capital ou infraestrutura e órgãos coletivos envolvendo participantes do cluster; e

- Agências governamentais e outros órgãos reguladores que exerçam influência.

Schmitz (1995) aponta que os pressupostos fundamentais para o sucesso de um cluster seriam: a flexibilidade das fronteiras entre as firmas; a relação entre essas fronteiras, caracterizada tanto por competição quanto por cooperação; a existência de confiança e reciprocidade. Esse autor ainda observa que a existência de competição entre firmas concorrentes não exclui necessariamente a ação conjunta para a resolução de problemas específicos e comuns. Um desses problemas comuns pode ser a aquisição de produtos e serviços.

\subsection{Compras conjuntas}

Conforme Tella \& Virolainen (2005), compras em grupo são uma cooperação horizontal entre organizações independentes que reuniram suas compras a fim de obter vários benefícios. A Figura 1 ilustra a definição desses autores, na qual se pode verificar que embora compras em grupo originem-se de cooperação horizontal, elas envolvem também a perspectiva de relacionamento interorganizacional vertical.

Schotanus \& Telgen (2007) definem compras conjuntas como a cooperação entre duas ou mais organizações em uma ou mais etapas de um processo de compras por meio do compartilhamento e/ou da união de seus volumes de compra, informação e/ou recursos.

Tella \& Virolainen (2005) apontam que os principais motivos para a formação de grupos de compras são:

- Obtenção de informações sobre potenciais fornecedores;

- Adquirir os suprimentos a custos reduzidos, devido ao maior volume do pedido;

- Redução de gastos, devido à economia de esforço e tempo na aquisição de produtos;

- Melhoria na qualidade e no gerenciamento da cadeia de suprimentos.

Para Schotanus \& Telgen (2007), existem ainda outras vantagens obtidas através da formação desses grupos, como: redução de riscos de suprimento; aprendizado mútuo e redução de custos logísticos.

Por outro lado existem fatores negativos na formação dos grupos de compra, que podem inviabilizá-los. Os principais fatores negativos na formação de grupos de compras apontados por alguns autores (Tella \& Virolainen, 2005; Schotanus \& Telgen, 2007) são:

- Fornecedores que não têm capacidade de atender toda a demanda do grupo de empresas;

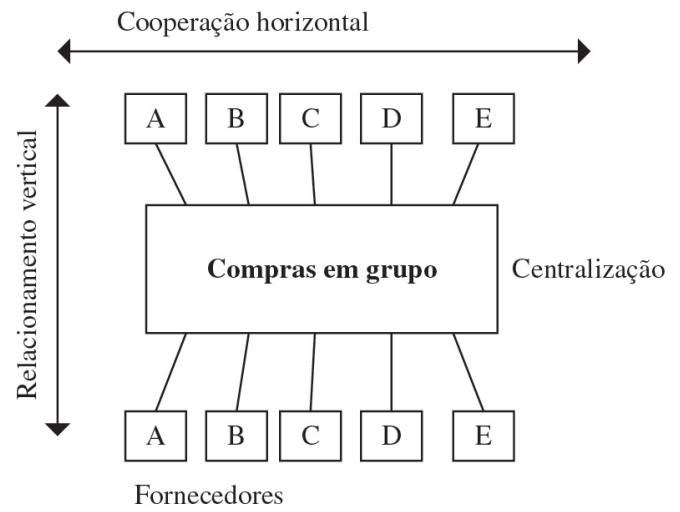

Figura 1. Conceito de compras em grupo. Fonte: Tella \& Virolainen (2005). 
- Desconfiança de que algumas empresas associadas ao grupo, após obterem as informações sobre os fornecedores, se desligarão do grupo para poder usufruir dessas informações de caráter confidencial em benefício próprio;

- Custos na formação e manutenção do grupo;

- Perda de flexibilidade nos pedidos, ou seja, diminui-se a diversidade de compra de produtos diferentes, com o intuito de criar grandes lotes dos mesmos produtos;

- Resistência dos fornecedores para venderem ao grupo de empresas.

Schotanus \& Telgen (2007) ainda levantaram os principais fatores que influenciam no sucesso dos grupos de compra em uma pesquisa levantamento realizada nos agrupamentos da Holanda:

- Formalização do grupo - As empresas do grupo devem estar formalmente comprometidas, através de contratos em que constem suas obrigações e direitos dentro do grupo;

- Cooperação dos membros do grupo e comunicação - São necessários conhecimento e esforço para coordenar as atividades do grupo e um sistema de comunicação eficiente entre os membros para proporcionar uma sincronia de especificações de suprimentos e preferências por fornecedores;

- Comprometimento e suporte interno - As empresas associadas não devem trocar seus representantes, para não atrapalhar a curva de aprendizado;

- Objetivos comuns e influência de cada membro no grupo;

- Alocação justa das economias.

\subsection{A lei brasileira e a questão das compras conjuntas}

A Constituição Federal Brasileira de 1988 (Brasil, 1988) estabelece tratamento diferenciado de favorecimento às microempresas e empresas de pequeno porte através dos artigos 170 e 179, via incentivo de simplificação de suas obrigações administrativas, tributárias, previdenciárias e creditícias.

Nesse sentido, foi promulgada a Lei Geral das Micro e Pequenas Empresas, mais especificamente a Lei Complementar número 123, de 14 de dezembro de 2006 (Brasil, 2006) que criou um regime diferenciado de tributação desse segmento e unificou impostos e contribuições pagos a união, estados e municípios. Além disso, prevê facilidade de acesso ao crédito, menor burocracia e tratamento preferencial nas licitações públicas.

Cabe ressaltar ainda que o associativismo também apresenta foro constitucional no Brasil (1988), através do artigo $5^{\circ}$, inc. $\mathrm{XVIl}$, que o prescreve como direito fundamental.

Com essa fundamentação jurídica, a Lei 123/2006 trouxe em seu escopo a criação do Consórcio Simples, entidade jurídica composta de empresas optantes pelo Simples Nacional, com o intuito de realizar negócios de compra e venda de bens e serviços, nos mercados nacional e internacional, por prazo indeterminado.

No entanto, para a lei brasileira, a possibilidade de constituição de consórcio limita-se às micro e pequenas empresas. Para empresas de maior porte, ou que não se enquadram na Lei 123/2006, em geral, as práticas adotadas no mercado são as seguintes:

- Compra e venda através de empresas de distribuição, cujos sócios são as empresas associadas. A rede de empresas reúne os pedidos das empresas associadas e efetua a compra em nome da própria rede e depois há o repasse dessas mercadorias para outras empresas. Essa prática implica na bitributação, uma vez que a fatura unificada deve ser fracionada para ser entregue ao destinatário;

- Compra ou venda em conjunto, porém com faturamento individual para cada empresa associada. No caso de compras em conjunto os produtos adquiridos pelos fornecedores são faturados individualmente, ou seja, empresa por empresa, também sendo entregues de maneira individual. Nessa prática não há bitributação. No entanto, os custos administrativos e logísticos do fornecedor e o esforço de negociação do comprador tendem a ser maiores.

\section{Método de pesquisa}

0 método pesquisa levantamento mostrou-se mais adequado para atender aos objetivos de pesquisa propostos pelo trabalho, pois permite a quantificação e processamento das variáveis estudadas e a construção do modelo de compras conjuntas adotado pelas empresas pertencentes aos APLs de Minas Gerais.

A pesquisa levantamento qualitativa se mostrou necessária, já que vários estudos sobre fatores de sucesso para cooperação interorganizacional têm sido realizados mas apenas um número limitado de estudos fornece uma ampla investigação empírica sobre os fatores de sucesso para cooperação interorganizacional (Hoffmann \& Schlosser, 2001). Outra razão foi buscar reduzir a lacuna entre a teoria e a prática da gestão, o que aumenta a utilidade da pesquisa para os profissionais e o reconhecimento científico da Engenharia de Produção (Forza, 2002).

Para Forza (2002), o processo da pesquisa levantamento é longo e pressupõe a pré-existência de um modelo teórico, que foi estruturado para este trabalho através dos construtos e hipóteses. A pesquisa 
levantamento ainda inclui os seguintes subprocessos: o processo de tradução do domínio teórico para o empírico; de desenho e teste da pesquisa; de coleta de dados para testar a teoria; a análise de dados; e, por fim, de resultados e conclusões.

\subsection{Ligação com o nível teórico: construtos e hipóteses}

Construtos constituem o conjunto de conhecimentos acerca de um assunto. Os construtos deste trabalho puderam ser validados de duas maneiras:

- Pesquisa qualitativa realizada por Schotanus (2007), que identificou alguns fatores importantes para o gerenciamento de grupos de compras através da realização de um estudo de caso nos grupos de compras das várias agências pertencentes às Nações Unidas. Essa pesquisa foi utilizada para suportar a construção da pesquisa levantamento que Schotanus (2007) conduziu em empresas da Holanda.

- Revisão, análise e classificação da literatura sobre compras conjuntas, buscando trabalhos cujo tema principal ou secundário fosse compras em grupo. Foram consultadas todas as bases de dados disponíveis no Portal Periódicos da CAPES (Coordenação de Aperfeiçoamento de Pessoal de Nível Superior) na busca de trabalhos relevantes sobre os temas em questão. As seguintes bases de pesquisa foram consultadas (número de artigos com citações relacionadas ao tema entre parênteses): AAAS, AAP, Academic Search Premier, ACM, ACS, AIP, AMA, American Academy of Psychiatry and the Law, American Association of Critical Care Nurses, APS, APA, American Society of Agronomy, Annual Reviews, ASN, Begell House, Bentham Science, BioOne,
British Medical Journal Publising Group, Cambridge University Press (1), Duke University Press, EBSCO (2), Emerald (2), Gale (2), Guilford Press, HighWire Press, IEEE (1), INFORMS (4), IOP, JSTOR, Karger, Maney Publishing, Nature, OECD, OVID, Oxford University Press, Red CLACSO, ProQuest, Sage (1), SciELO, Science Direct (12), Slack Inc., Springer (1), Thieme, Willey-Blackwell (7), Wilson e World Scientific.

- 0 principal resultado da revisão foi o mapeamento dos benefícios da prática de compras conjuntas, encontrados nas bases de dados pesquisadas, conforme apresentados na Tabela 1.

Considerando que uma hipótese é uma conjuntura lógica relacionada entre duas ou mais variáveis (medidas) expressas na forma de teste de hipóteses (Forza, 2002), a pesquisa foi estruturada para que cada construto possuísse duas hipóteses, o que permite uma melhor análise dos dados coletados. A Tabela 2 apresenta os construtos contextualizados, com as respectivas proposições e hipóteses. Os construtos têm por intuito estruturar o modelo de compras adotado pelas empresas pertencentes aos APLs.

\subsection{Etapas da pesquisa levantamento}

0 método de coleta de dados escolhido foi o questionário disponibilizado em formulário específico na internet (web-survey). Utilizou-se também a sugestão de Forza (2002), em que o pesquisador e sua equipe realizaram contatos telefônicos para melhorar a taxa de resposta através de notificações anteriores ao envio do instrumento.

Foi realizado também um pré-teste com o objetivo de identificar e eliminar potenciais problemas

Tabela 1. Benefícios da compra conjunta, respectivos códigos e número de citações.

\begin{tabular}{lcc}
\hline \multicolumn{1}{c}{ Benefícios } & Número de citações & Alinhado ao construto \\
\hline Aumento da transparência no processo de aquisição & 2 & Comunicação \\
Aumento do conhecimento da empresa & 2 & Processo \\
Aumento do poder de compras & 1 & Compras \\
Compartilhamento de informações & 5 & Comunicação \\
Diminuição de custos & 12 & Processos \\
Diminuição dos riscos de suprimentos & 1 & Compras \\
Divisão da carga de trabalho & 2 & Processo \\
Maior variedade de produtos adquiridos & 2 & Compras \\
Melhor gerenciamento dos estoques & 1 & Processo \\
Melhor relacionamento com fornecedores & 5 & Compras \\
Melhoria da qualidade da empresa & 7 & Processo \\
Melhoria das condições de negociação & 1 & Compras \\
Melhoria no processo de compras & 5 & Processo \\
Melhoria na comunicação & 1 & Comunicação \\
Padronização de produtos das empresas associadas & 1 & Compras \\
Preços menores de aquisção & 14 & Compras \\
Redução dos custos administrativos & 1 & Processos \\
Redução dos custos de transação & 2 & Processos \\
\hline
\end{tabular}


Tabela 2. Construto e hipóteses da pesquisa.

\begin{tabular}{|c|c|}
\hline Construto 1 & Compras: visa medir como a compra conjunta influencia e modifica o ato de aquisição de mercadorias. \\
\hline Proposição a. & Aumento do poder de compra e melhoria das condições de negociação; \\
\hline Hipótese & P1: Compras conjuntas estão positivamente associadas ao aumento de poder de compra e da melhoria de negociações. \\
\hline Proposição b. & Melhor qualidade dos produtos e/ou serviços comprados; \\
\hline Hipótese & P2: Compras conjuntas estão positivamente associadas à melhoria de produto e serviços comprados. \\
\hline Construto 2 & Comunicação: visa analisar como se dá a troca de informações entre as empresas participantes de um grupo de compras. \\
\hline Proposição a. & $\begin{array}{l}\text { Aumento do compartilhamento de informações com outras organizações (por exemplo, compartilhar informações de preços } \\
\text { de produtos fornecidos, práticas, processo e métodos compartilhados); }\end{array}$ \\
\hline Hipótese & $\begin{array}{l}\text { P3: Compras conjuntas estão positivamente associadas ao aumento do compartilhamento de informações, à manutenção de } \\
\text { comunicação mútua e atual sobre projetos. }\end{array}$ \\
\hline Proposição b. & Utilização em benefício próprio de informações confidenciais de outras empresas do grupo; \\
\hline Hipótese & P4: Compras conjuntas estão positivamente propensas à utilização de informações confidenciais em benefício próprio. \\
\hline Proposição c. & Aumento da transparência no processo de aquisição devido à troca de informações; \\
\hline Hipótese & $\begin{array}{l}\text { P5: Compras conjuntas estão positivamente associadas ao aumento da transparência no processo de aquisição das empresas } \\
\text { do grupo. }\end{array}$ \\
\hline Construto 3 & $\begin{array}{l}\text { Processos e organização: visa analisar como se dão os novos processos e a nova organização montada para atender a } \\
\text { prática da compra conjunta. }\end{array}$ \\
\hline Proposição a. & Melhoria do processo de compras, devido ao compartilhamento de informações e recursos; \\
\hline Hipótese & P6: Compras conjuntas estão positivamente associadas à melhoria do processo de compras das organizações envolvidas. \\
\hline Proposição b. & Todos os membros têm influência similar nas atividades do grupo e decisões e a participação é voluntária; \\
\hline Hipótese & $\begin{array}{l}\text { P7: Compras conjuntas estão positivamente associadas à similaridade da influência dos membros nas atividades do grupo e } \\
\text { à participação voluntária. }\end{array}$ \\
\hline Proposição c. & Métodos mais justos de compartilhamento de ganhos financeiros e divisão de custos para permitir a equidade no grupo; \\
\hline Hipótese & $\begin{array}{l}\text { P8: Compras conjuntas estão positivamente associadas à aplicação de métodos justos para compartilhamento dos ganhos e } \\
\text { divisão dos custos em comum. }\end{array}$ \\
\hline Construto 4 & $\begin{array}{l}\text { Associativismo/cooperação: visa medir qual a importância de práticas de associativismo e cooperação aliadas à formação de } \\
\text { grupo de compras. }\end{array}$ \\
\hline Proposição a. & Formação de grupos de compras intensivos inclui empenho e apoio interno da organização; \\
\hline Hipótese & P9: Compras conjuntas estão positivamente associadas ao empenho e apoio interno da organização. \\
\hline Proposição b. & Formação de grupos de compras intensivos inclui formalidade do grupo e uniformidade dos membros; \\
\hline Hipótese & P10: Compras conjuntas estão positivamente associadas à criação da formalidade do grupo e uniformidade dos membros. \\
\hline Proposição c. & $\begin{array}{l}\text { Todos os membros devem contribuir com recursos, conhecimentos e esforços comparáveis, assim como cumprirem os } \\
\text { compromissos firmados; }\end{array}$ \\
\hline Hipótese & $\begin{array}{l}\text { P11: Compras conjuntas estão positivamente associadas à contribuição em recursos, conhecimentos e esforços equivalentes } \\
\text { e ao cumprimento dos compromissos firmados pelos membros. }\end{array}$ \\
\hline
\end{tabular}

antes do envio do questionário para a amostra escolhida aleatoriamente. A análise concentrou-se no conteúdo das perguntas, enunciados, termos utilizados, sequência, formato, tempo de resposta, dificuldades e as instruções para preenchimento. Foram selecionados respondentes das três categorias, conforme sugestão de Forza (2002): pesquisadores acadêmicos ligados ao tema, profissionais da área e duas empresas participantes da população, que foram posteriormente retirados do sorteio para escolha da amostra.

0 questionário foi dividido em duas partes. 0 instrumento de coleta inicia-se com as instruções de preenchimento, seguidas pela primeira parte com questões acerca da caracterização da empresa pertencente ao APL e por fim estabelece questionamentos sobre a caracterização do grupo de compras. As questões de multiescolha foram estruturadas através da escala Likert de cinco pontos. As perguntas da segunda parte do questionário foram elaboradas com base nos construtos levantados, buscando-se estabelecer o modelo de compras conjuntas adotado. 0 respondente somente teria acesso a essa parte do questionário se a resposta à pergunta "Quantas compras conjuntas foram feitas na sua organização, nos últimos três anos?” fosse maior ou igual a uma compra; já que não faz sentido o entrevistado responder questões acerca de compras conjuntas se sua empresa não participa de tal processo.

A pesquisa ficou delimitada ao estado de Minas Gerais devido ao apoio da Fundação de Amparo à Pesquisa de Minas Gerais (FAPEMIG) ao projeto e também porque o estado possui uma quantidade satisfatória de Arranjos Produtivos Locais industriais, sendo a população alvo do trabalho composta pelas empresas pertencentes aos Arranjos Produtivos Locais Mineiros. Segundo o Grupo de Trabalho Permanente para Arranjos Produtivos Locais (Brasil, 2008), os APLs mineiros, com as respectivas cidades sede, são:

- APL de Fundição, Belo Horizonte;

- APL de Móveis, Ubá; 
- APL de Biotecnologia, Belo Horizonte;

- APL de Fogos de Artifício, Santo Antônio do Monte;

- APL de Calçados, Nova Serrana;

- APL de Eletrônicos, Santa Rita do Sapucaí;

- APL de Gemas e Joias, Nova Lima.

Com essas informações, foram procuradas as organizações gestoras dos APLs citados para obterem-se os contatos das empresas pertencentes a esses arranjos. No entanto, o Sindijoias (organização gestora do APL de Gemas e Joias) respondeu que atualmente as empresas não estão organizadas na forma de APL, apesar de assim constar no levantamento do MDIC, e não informou quais são as empresas que pertencem ao sindicato. Já a organização gestora do APL de Fundição simplesmente não forneceu nenhuma informação após várias tentativas de contato do pesquisador. Assim, esses dois APLs foram retirados da pesquisa.

Como as empresas participantes da população pertenciam a APLs diferentes, adotou-se a solução proposta por Forza (2002) de dividir a população em estratos e realizar uma seleção aleatória dos elementos. Os estratos foram identificados com base em cada Arranjo Produtivo Local. Após esse levantamento, deu-se prosseguimento ao processo de pesquisa, realizando-se a escolha aleatória das empresas a serem pesquisadas e depois aplicando-se o questionário de coleta de dados (Cauchick Miguel \& Ho, 2010) (Tabela 3).

Iniciou-se a coleta de dados através do envio de e-mails para a amostra aleatória selecionada, com a explicação dos objetivos da pesquisa e endereço da página da internet para preenchimento do questionário. Essa ação foi denominada etapa 1. Quando alguma empresa da amostra não respondia o questionário, dava-se início à etapa posterior, que consistia na realização de ligações telefônicas para notificar o envio do e-mail e reafirmar o pedido para preenchimento do questionário (etapa 2). A etapa 3 foi o reenvio do e-mail para as empresas que não responderam o questionário. A etapa 4, última ação antes da seleção de nova amostra de empresas, consistiu na realização de ligações telefônicas para notificar e reafirmar o pedido de preenchimento do questionário. A Figura 2 ilustra o processo do desenvolvimento da pesquisa.

Tabela 3. Estratificação do número de empresas a serem entrevistas.

\begin{tabular}{lccc}
\hline \multicolumn{1}{c}{ Arranjo Produtivo Local } & Número de empresas & \% do total da população & $\begin{array}{c}\text { Número de empresas a serem } \\
\text { entrevistas }\end{array}$ \\
\hline APL Eletrônicos & 100 & $14 \%$ & 36 \\
APL Biotecnologia & 23 & $3 \%$ & 8 \\
APL Móveis & 110 & $15 \%$ & 39 \\
APL Fogos de Artifício & 35 & $5 \%$ & 12 \\
APL Calçados & 460 & $63 \%$ & 164 \\
Total da população & 728 & $100 \%$ & 259 \\
\hline
\end{tabular}

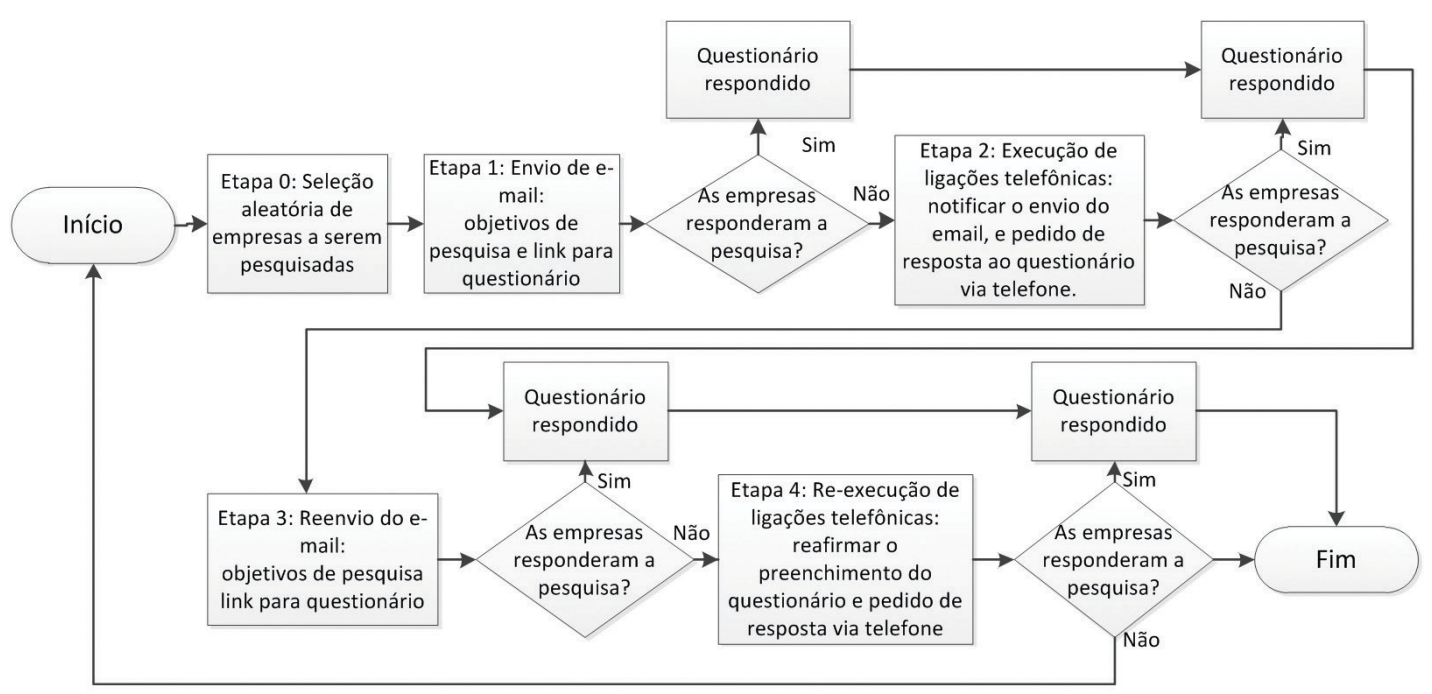

Figura 2. Processo da pesquisa levantamento. 


\subsection{Análise dos dados e resultados das empresas pertencentes aos Arranjos Produtivos Locais}

Inicialmente, a amostra foi caracterizada através das questões iniciais do instrumento de coleta de dados, que tinham justamente esse objetivo. Assim, esses dados forneceram informações importantes que ajudaram a identificar as características da amostra. Em um segundo momento, a expectativa era utilizarem-se técnicas de estatística multivariada para analisar os dados e testar as hipóteses, já que a análise multivariada implica na análise simultânea de três ou mais variáveis (Bryman \& Bell, 2007).

A taxa de resposta total ficou em 37,4\%, apresentada na Tabela 4, que também indica as taxas de respostas obtidas para cada APL pesquisado. Frohlic (2002) analisou 233 artigos sobre pesquisas levantamento na área de Gestão de Operações, publicados de 1990 a 2002, e encontrou uma taxa de resposta média a questionários de aproximadamente $32 \%$. Portanto, a taxa de resposta geral da pesquisa foi considerada satisfatória, já que está acima dessa média. No entanto, para se atingir essa taxa várias amostras foram levantadas, realizando-se várias etapas de aplicação do questionário.

\subsection{Caracterização da amostra das empresas pertencentes aos Arranjos Produtivos Locais}

Cargo dos respondentes da pesquisa, considerando o total de participantes: diretores ou proprietários, 25\%; supervisores, 6\%; gerentes, 24\%; compradores, $28 \%$; e assistentes ou auxiliares, $17 \%$.
Apesar de o foco da pesquisa ser a análise de arranjos industriais, é importante ressaltar que nesses locais há outros segmentos empresariais atuantes, como o comércio e a prestação de serviços, que predominantemente fornecem para as indústrias. Do total de 259 empresas, $76 \%$ atuam no segmento da indústria; 24\% no comércio; e apenas 1\% na prestação de serviços.

0 reconhecimento da contribuição da função compras ao sucesso da organização pela diretoria das empresas apresenta semelhanças, com relação a importância e atenção, a confiança que a diretoria das empresas deposita no departamento de compras. Portanto, foi calculada a intensidade da relação linear para as respostas apresentadas na Tabelas 5 e 6 , buscando verificar se há relacionamento linear entre essas duas variáveis.

Foi utilizado o cálculo do coeficiente de Correlação Linear (Coeficiente de Pearson) para determinar o grau de correlação entre as variáveis. A correlação entre as variáveis referentes ao departamento de compras e o reconhecimento da função compras resultou no valor de 0,602, considerada uma correlação moderadamente positiva, segundo interpretação do coeficiente apresentado na Tabela 7. Sendo assim, existe coesão entre os resultados das indagações apresentadas nas Tabelas 5 e 6 .

As Tabelas 8, Prioridade para compras conjuntas, 9, Preparação para compras conjuntas, e 10, Oportunidades para compras conjuntas, nos últimos dois anos, também apresentam temática semelhante, pois referem-se ao grau de afinidade do tema compras conjuntas nas empresas pesquisadas. Assim, também foi

Tabela 4. Número de empresas levantadas por tipo de amostra, total de empresas contatadas, total de empresas respondentes e taxa de resposta.

\begin{tabular}{|c|c|c|c|c|c|c|}
\hline $\begin{array}{l}\text { Número de empresas } \\
\text { da amostra }\end{array}$ & APL Móveis & $\begin{array}{c}\text { APL } \\
\text { Biotecnologia }\end{array}$ & $\begin{array}{l}\text { APL Fogos de } \\
\text { Artifício }\end{array}$ & APL Calçados & APL Eletrônicos & Total \\
\hline Amostra A & 39 & 8 & 12 & 164 & 36 & 259 \\
\hline Amostra B & 39 & 8 & 12 & 164 & 36 & 259 \\
\hline Amostra C & 32 & & 11 & 132 & & 175 \\
\hline Total de empresas contatadas & 110 & 16 & 35 & 460 & 72 & 693 \\
\hline $\begin{array}{l}\text { Total de empresas que } \\
\text { responderam ao questionário }\end{array}$ & 39 & 8 & 12 & 164 & 36 & 259 \\
\hline Taxa de resposta & $35,5 \%$ & $50,0 \%$ & $34,3 \%$ & $35,7 \%$ & $50,0 \%$ & $37,4 \%$ \\
\hline
\end{tabular}

Tabela 5. Referência do departamento de compras à diretoria.

\begin{tabular}{|c|c|c|c|c|c|c|c|}
\hline $\begin{array}{l}0 \text { departamento de compras na } \\
\text { nossa organização reporta-se } \\
\text { diretamente à diretoria }\end{array}$ & $\begin{array}{c}\mathrm{APL} \\
\text { Eletrônicos }\end{array}$ & $\begin{array}{c}\text { APL } \\
\text { Biotecnologia }\end{array}$ & APL Móveis & $\begin{array}{l}\text { APL Fogos } \\
\text { de Artifício }\end{array}$ & $\begin{array}{c}\text { APL } \\
\text { Calçados }\end{array}$ & Total & $\%$ total \\
\hline Discordo totalmente & 0 & 0 & 0 & 0 & 0 & 0 & $0 \%$ \\
\hline Discordo parcialmente & 0 & 0 & 0 & 0 & 0 & 0 & $0 \%$ \\
\hline Não concordo nem discordo & 0 & 0 & 0 & 0 & 0 & 0 & $0 \%$ \\
\hline Concordo parcialmente & 15 & 2 & 19 & 0 & 15 & 51 & $20 \%$ \\
\hline Concordo totalmente & 21 & 6 & 20 & 12 & 149 & 208 & $80 \%$ \\
\hline Total & 36 & 8 & 39 & 12 & 164 & 259 & $100 \%$ \\
\hline
\end{tabular}


Tabela 6. Reconhecimento da contribuição da função compras ao sucesso da empresa pela diretoria das empresas.

\begin{tabular}{|c|c|c|c|c|c|c|c|}
\hline $\begin{array}{l}\text { Nossa diretoria reconhece que } \\
\text { a função compras contribui } \\
\text { significativamente para o } \\
\text { sucesso de nossa organização }\end{array}$ & $\begin{array}{c}\text { APL } \\
\text { Eletrônicos }\end{array}$ & $\begin{array}{c}\text { APL } \\
\text { Biotecnologia }\end{array}$ & APL Móveis & $\begin{array}{l}\text { APL Fogos } \\
\text { de Artifício }\end{array}$ & $\begin{array}{c}\text { APL } \\
\text { Calçados }\end{array}$ & Total & $\%$ do total \\
\hline Discordo totalmente & 0 & 0 & 0 & 0 & 0 & 0 & $0 \%$ \\
\hline Discordo parcialmente & 0 & 0 & 0 & 0 & 0 & 0 & $0 \%$ \\
\hline Não concordo nem discordo & 0 & 0 & 0 & 0 & 0 & 0 & $0 \%$ \\
\hline Concordo parcialmente & 11 & 0 & 0 & 0 & 15 & 26 & $10 \%$ \\
\hline Concordo totalmente & 25 & 8 & 39 & 12 & 149 & 233 & $90 \%$ \\
\hline Total & 36 & 8 & 39 & 12 & 164 & 259 & $100 \%$ \\
\hline
\end{tabular}

Tabela 7. Interpretação do coeficiente de correlação.

\begin{tabular}{cc}
\hline Coeficiente de correlação & Interpretação do grau de correlação \\
\hline$\rho=1$ & Perfeita positiva \\
$0,8 \leq \rho<1$ & Forte positiva \\
$0,5 \leq \rho<0,8$ & Moderadamente positiva \\
$0,1 \leq \rho<0,5$ & Fraca positiva \\
$0 \leq \rho<0,1$ & Ínfima positiva \\
$\rho=0$ & Nula \\
$-0,1 \leq \rho<0$ & Ínfima negativa \\
$-0,5 \leq \rho<-0,1$ & Fraca negativa \\
$-0,8 \leq \rho<-0,5$ & Moderadamente negativa \\
$-1 \leq \rho<-0,8$ & Forte negativa \\
$\rho=-1$ & Perfeita negativa \\
\hline
\end{tabular}

Fonte: Santos (2007).

realizado o cálculo de Correlação Linear, que retornou os seguintes resultados, obtidos da interpretação dos resultados da Tabela 7:

- Correlação entre prioridade para compras conjuntas e preparação para compras conjuntas: 0,344 ; uma correlação fraca, no entanto positiva. Portanto há relação mútua entre essas variáveis;

- Correlação entre prioridade para compras conjuntas e oportunidades para compras conjuntas nos últimos dois anos: 0,307; também há uma correlação positiva e fraca, sendo que há um pequeno relacionamento entre as duas variáveis em questão;

- Correlação entre preparação para compras conjuntas e oportunidades para compras conjuntas nos últimos dois anos: 0,192 ; o mesmo da correlação anterior pode ser compreendido nesse caso, há correlação fraca, porém positiva. Então, uma vez mais, as variáveis estão relacionadas.

Esses dados de correlação podem indicar que há uma falta de governança e coordenação das organizações gestoras nos APLs mineiros.

\subsection{Teste de hipóteses das empresas pertencentes aos Arranjos Produtivos Locais}

0 fato mais marcante na análise das respostas recebidas foi que a grande maioria (255) das 259 empresas pesquisadas respondeu 0 (zero) para a pergunta: "Quantas compras conjuntas foram feitas na sua organização, nos últimos três anos?" Com essa resposta, as empresas não respondiam à segunda parte do questionário, uma vez que não tinham tido experiências com compras conjuntas. Consequentemente, não havia maneira de realizar-se o teste de hipótese. Assim, apenas quatro empresas responderam a todo o questionário, sendo duas delas pertencentes ao APL Eletrônicos e duas pertencentes ao APL Fogos de Artifício.

Indagadas se continuaram com o processo de compras conjuntas, as empresas que organizaram grupos de compras piloto nos respectivos APLs citados responderam que as compras em grupo foram apenas algumas experiências realizadas para verificar se seria possivel adotar essa prática sistematicamente no APL.

A partir dos resultados encontrados foram feitos contatos com os gestores dos Arranjos Produtivos Locais de Eletrônicos e de Fogos de Artifício. Os gestores apontaram as principais razões que impediram o desenvolvimento dos grupos de compra coletiva:

- As empresas não querem compartilhar informações de suprimentos e nem os bons relacionamentos conquistados com fornecedores que consideram estratégicos;

- Devido à grande diversidade de produtos, com diversas alternativas, as empresas preferiram manter suas opções de fornecimento, com vistas a não perderem vantagens competitivas e diferenciação de mercado;

- Nas experiências realizadas, para alguns lotes de compras conjuntas uniram-se empresas com disparidade de tamanho. Isso foi prejudicial ao processo, já que, segundo os gestores, a empresa com porte maior sentiu que a compra conjunta não lhe trouxe vantagens, diferentemente da empresa de menor porte, que conseguiu obter uma melhor condição de fornecimento. Em geral, as empresas menores não compram grandes volumes e não possuem poder de barganha junto a alguns fornecedores;

- As empresas tiveram receio de que a demanda não seria atendida pelos fornecedores no prazo necessitado devido ao grande volume do lote; 
Tabela 8. Prioridade para compras conjuntas.

\begin{tabular}{lccccccc}
\hline $\begin{array}{c}\text { Prioridade para } \\
\text { compras conjuntas }\end{array}$ & $\begin{array}{c}\text { APL } \\
\text { Eletrônicos }\end{array}$ & $\begin{array}{c}\text { APL } \\
\text { Biotecnologia }\end{array}$ & APL Móveis & $\begin{array}{c}\text { APL Fogos } \\
\text { de Artifício }\end{array}$ & APL Calçados & Total & \% do total \\
\hline Muito baixa & 31 & 6 & 4 & 10 & 99 & 150 & $59 \%$ \\
Baixa & 5 & 0 & 31 & 2 & 53 & 91 & $35 \%$ \\
Nem baixa, nem elevada & 0 & 0 & 4 & 0 & 12 & 16 & $6 \%$ \\
Elevada & 0 & 0 & 0 & 0 & 0 & 0 & $0 \%$ \\
Muito elevada & 0 & 0 & 0 & 0 & 0 & 0 & $0 \%$ \\
Total & 36 & 6 & 39 & 12 & 164 & 257 & $100 \%$ \\
\hline
\end{tabular}

Tabela 9. Preparação para compras conjuntas.

\begin{tabular}{lccccccc}
\hline $\begin{array}{c}\text { Preparação para compras } \\
\text { conjuntas }\end{array}$ & $\begin{array}{c}\text { APL } \\
\text { Eletrônicos }\end{array}$ & $\begin{array}{c}\text { APL } \\
\text { Biotecnologia }\end{array}$ & APL Móveis & $\begin{array}{c}\text { APL Fogos de } \\
\text { Artifício }\end{array}$ & APL Calçados & Total & \% do total \\
\hline Muito pouco & 15 & 4 & 15 & 8 & 105 & 147 & $57 \%$ \\
Pouco & 5 & 0 & 16 & 0 & 51 & 72 & $28 \%$ \\
Nem pouco, nem & 16 & 3 & 4 & 4 & 8 & 35 & $14 \%$ \\
frequentemente & 0 & 1 & 4 & 0 & 0 & 5 & $2 \%$ \\
Frequentemente & 0 & 0 & 0 & 0 & 0 & 0 & $0 \%$ \\
Muito frequentemente & 36 & 8 & 39 & 12 & 164 & 259 & $100 \%$ \\
Total & & &
\end{tabular}

Tabela 10. Oportunidades para compras conjuntas nos últimos dois anos.

\begin{tabular}{lccccccc}
\hline $\begin{array}{l}\text { Oportunidades para compras } \\
\text { conjuntas nos últimos 2 anos }\end{array}$ & $\begin{array}{c}\text { APL } \\
\text { Eletrônicos }\end{array}$ & $\begin{array}{c}\text { APL } \\
\text { Biotecnologia }\end{array}$ & APL Móveis & $\begin{array}{c}\text { APL Fogos } \\
\text { de Artificio }\end{array}$ & APL Calçados & Total & \% do total \\
\hline Muito pouco & 27 & 4 & 28 & 9 & 99 & 167 & $64 \%$ \\
Pouco & 0 & 0 & 7 & 3 & 65 & 75 & $29 \%$ \\
$\begin{array}{l}\text { Nem pouco, nem } \\
\text { frequentemente }\end{array}$ & 9 & 4 & 4 & 0 & 0 & 17 & $7 \%$ \\
Frequentemente & 0 & 0 & 0 & 0 & 0 & 0 & $0 \%$ \\
Muito frequentemente & 0 & 0 & 0 & 0 & 0 & 0 & $0 \%$ \\
Total & 36 & 8 & 39 & 12 & 164 & 259 & $100 \%$ \\
\hline
\end{tabular}

- Finalmente, alegaram que iriam perder o contato direto com os fornecedores e, consequentemente, que seria bastante difícil resolver possíveis problemas como produtos entregues não conformes ou com defeitos.

Vale lembrar que a segunda parte do questionário era composta por questões que tinham como objetivo testar as hipóteses levantadas através dos construtos da pesquisa. Portanto, diante dos resultados encontrados não foi possível estruturar um modelo de compras conjuntas a ser adotado nos Arranjos Produtivos Locais do setor industrial do estado de Minas Gerais.

\section{Conclusões}

Com os resultados da pesquisa levantamento pôde-se verificar que as compras conjuntas em Arranjos Produtivos Locais mineiros são incipientes e não sistemáticas. De acordo com os dados da amostra pesquisada, apenas algumas tentativas de compras conjuntas foram realizadas nas empresas pertencentes ao APL de Eletrônicos e ao APL de Fogos de Artifício. Assim, não foi possível determinar um modelo de compras de colaboração em APLs industriais mineiros. Diante dos resultados encontrados, foram levantadas possíveis causas da pouca utilização da prática das compras conjuntas nesses APLs, associadas ao entendimento geral das empresas de que poucas vantagens podem ser obtidas a partir da adoção de uma política de compras colaborativa.

Com base nos resultados aqui obtidos, futuros trabalhos poderão analisar se o método de compras conjuntas é inadequado, pouco difundido e divulgado entre as empresas pertencentes aos APLs ou se esses APLs simplesmente não estão preparados para esse tipo de colaboração. Há de se ressaltar também que a pesquisa concentrou-se nos APLs industriais do estado de Minas Gerais e que assim outro desdobramento poderia ser a aplicação da pesquisa levantamento em outros estados ou em outros setores da economia, como as associações de empresas atuantes no varejo.

A construção de um modelo de cooperação entre empresas genuinamente brasileiro, que leve em conta as particularidades nacionais e até mesmo regionais é sem dúvida um tema de grande importância. 0 modelo nacional é necessário, pois se observa que as ações dos órgãos governamentais e de fomento estão baseadas fortemente em experiências internacionais, como os 
distritos industriais italianos (região conhecida como Terceira ltália) e de regiões de alta concentração de empresas de tecnologia nos Estados Unidos (Vale do Silício e Route 128). Como concluem Gerolamo et al. (2008, p. 362),

[...] embora as políticas de desenvolvimento de clusters e as redes de cooperação europeias apresentem resultados interessantes, tal estratégia não deve ser usada como uma panaceia para os problemas econômicos de diferentes regiões e países.

Fundamentalmente, interessa saber se existe e como se desenvolve a colaboração em outros aspectos, além dos relacionados às compras. Assim, são necessários estudos relacionados à colaboração dos arranjos interorganizacionais nos temas venda em grupo, publicidade e propaganda compartilhadas, colaboração em pesquisa e desenvolvimento de produtos, capacitação compartilhada de mão de obra, compartilhamento de maquinários e equipamentos, além de uma análise mais profunda com relação à colaboração com fornecedores, dentre outros temas colaborativos.

\section{Referências}

Aun, R. (2005). Strategic Sourcing: Definindo as estratégias de suprimentos e de relacionamento com os fornecedores. Institute for International Research, 1-58.

Brasil. (1988). Constituição (1988). Constituição da República Federativa do Brasil. Brasília: Senado.

Brasil. (2006). Institui o Estatuto Nacional da Microempresa e da Empresa de Pequeno Porte (Lei Complementar número 123, de 14 de dezembro de 2006). Brasília: Senado.

Brasil, Ministério do Desenvolvimento, Indústria e Comércio Exterior. (2008). Levantamento institucional de Arranjos Produtivos Locais (APLs). Retrieved from http://www. desenvolvimento.gov.br/sitio/sdp/ proAcao/arrProLocais/ arrProLocais.php.

Bryman, A., \& Bell, E. (2007). Business Research Methods. (2nd ed.). Nova lorque: Oxford.

Cauchick Miguel, P. A., \& Ho, L. L. (2010). Levantamento tipo Survey. In A. Fleury, C. H. P. Mello, D. N. Nakano, J. B.Turrioni, R. Morabito, R. A. Martins, \& V. Pureza (Org.), Metodologia de Pesquisa em Engenharia de Produção e Gestão de Operações (pp. 73-123). Rio de Janeiro: Elsevier.

Cousins, P. D., Lawson, B., \& Squire, B. (2006). An empirical taxonomy of purchasing functions. Manchester Business School, The University of Manchester, Manchester. International Journal of Operations \& Production Management, 26(7), 775-794. http://dx.doi. org/10.1108/01443570610672239

Essig, M. (2000). Purchasing consortia as symbiotic relationships: developing the concept of "consortium sourcing”. European Journal of Purchasing \& Supply Management, (6), 13-22. http://dx.doi.org/10.1016/ S0969-7012(99)00031-3

Faes, W., Knight, L., \&Matthyssens, P. (2001). Buyer profiles: an empirical investigation of changing organizational requirements. European Journal of Purchasing \& Supply Management, 7(3), 197-208. http://dx.doi.org/10.1016/ S0969-7012(00)00031-9

Forza, C. (2002). Survey research in operations management: a process-based perspective. International Journal of Operations \& Production Management, 22(2), 152-194. http://dx.doi.org/10.1108/01443570210414310

Frohlic, M. T. (2002). Techniques for improving response rate in OM survey research. Journal of Operations Management, (20), 53-62. http://dx.doi.org/10.1016/ S0272-6963(02)00003-7

Gelderman, K., \& Van Weele, A. J. (2000). New perspectives on Kraljic's Purchasing Portfolio Approach. In Conference Proceedings of the 9th International Annual IPSERA Conference, London, Ontario.

Gerolamo, M. C., Carpinetti, L. C. R., Fleschutz, T., \& Seliger, G. (2008). Clusters e redes de cooperação de pequenas e médias empresas: observatório europeu, caso alemão e contribuições ao caso brasileiro. Gestão da Produção, 15(2), 351-365. http://dx.doi.org/10.1590/ S0104-530X2008000200011

Hoffmann, W., \& Schlosser, R. (2001). Success factors of strategic alliances in small and medium-sized enterprises, an empirical study. Long Range Planning, 34(3), 357381. http://dx.doi.org/10.1016/S0024-6301(01)00041-3

Kraljic, P. (1983). Purchasing must become supply management. Harvard Business Review, 61(5), 109-117.

Laforet, S. (2009). Effects of size, market and strategic orientation on innovation in non-high-tech manufacturing SMEs. European Journal of Marketing, 43(1/2), 188212. http://dx.doi.org/10.1108/03090560910923292

Mcadam, R., \& Armstrong, G. (2001). A symbiosis of quality and innovation in SMEs: a multiple case study analysis. Managerial Auditing Journal, 716), 394-399. http:// dx.doi.org/10.1108/02686900110398296

Morrissey, B., \& Pittaway, L. (2004). A study of procurement behaviour in small firms. Journal of Small Business and Enterprise Development, 11(2), 254-262. http://dx.doi. org/10.1108/14626000410537191

Murad, R. B. (2009). Gestão de Relacionamento com Fornecedores em Arranjos Produtivos Locais: o caso do Vale da Eletrônica (Dissertação de Mestrado). Universidade Federal de Itajubá, Itajubá.

Noronha, E. G., \& Turchi, L. (2005). Política industrial e ambiente institucional na análise de Arranjo produtivo Local. Brasília: IPEA. Texto para discussão n. 1076, 31 p. Retrieved from http://www.ipea.gov. brportalimagesstoriesPDFsTDstd_1076.pdf.

Porter, M. E. (1999). Aglomerados e competição: novas agendas para empresas, governos e instituições. Em Competição: estratégias competitivas essenciais. Rio de Janeiro: Campus.

Porter, M. E. (1998). Clusters and the new economics of competition. Harvard Business Review, 76(6), 77-90. PMid:10187248.

Santos, C. (2007). Estatística Descritiva: Manual de Autoaprendizagem. Lisboa: Edições Sílabo.

Schmitz, H. (1995). Collective Efficiency: growth path for smallscale industry. Journal of Development Studies, 31(4), 529566. http://dx.doi.org/10.1080/00220389508422377 
Schotanus, F. (2007). Horizontal Cooperative Purchasing (Tese de Doutorado). Universidade de Twente, Enschede, Holanda.

Schotanus, F., \& Telgen, J. (2007). Developing a typology of organisational forms of cooperative purchasing. Journal of Purchasing \& Supply Management, 13, 53-68. http:// dx.doi.org/10.1016/j.pursup.2007.03.002

Soderquist, K., Chanaron, J. J., \& Motwani, J. (1997). Managing innovation in French small and medium-sized enterprises: an empirical study. Benchmarking for Quality Management \& Technology, 4(4), 259-272. http:// dx.doi.org/10.1108/14635779710195104

Tella, E., \& Virolainen, V. M. (2005). Motives behind purchasing consortia. International Journal of Production Economics, 93(94), 161-168. http://dx.doi. org/10.1016/j.jpe.2004.06.014
Toledo, J. C., Silva, S. L., Mendes, G. H. S., \& Jugend, D. (2008). Fatores críticos de sucesso no gerenciamento de projetos de desenvolvimento de produto em empresas de base tecnológica de pequeno e médio porte. Gestão \& Produção, 15(1), 117-134. http://dx.doi.org/10.1590/ S0104-530X2008000100011

\section{Agradecimentos}

Os autores agradecem ao CNPq (Conselho Nacional de Desenvolvimento Científico e Tecnológico) e à FAPEMIG (Fundação de Amparo à Pesquisa do Estado de Minas Gerais) pelo apoio financeiro concedido a diversos projetos que subsidiaram o desenvolvimento desse trabalho.

\title{
Survey for an analysis of the cooperative purchasing model adopted by clusters of the state of Minas Gerais
}

\begin{abstract}
Although purchasing supplies represents a significant cost for many companies, the proper management of procurement function and relationships with suppliers can ensure greater competitiveness for their products and services, thus bringing better results to shareholders. However, this advantage still seems to be a privilege of large organizations. For internal and external constraints, small and medium companies are outside both the supplier relationship management and the correct management of purchases. Small and medium companies, when they aim to overcome the various managerial or technological limitations (among them the limitations related to supply chain management), can organize clusters that primarily work in the industrial sector. Companies that exist within a specific sector where there is both competition and practical cooperation create these organized clusters. Among these practices, the share and union of purchasing through the practice of cooperative purchasing can be called the main practice. From this context, the objective is to analyze the models for cooperative purchasing that have been adopted by manufacturing clusters and retailers buying offices, focused on the state of Minas Gerais. Thus, a research survey was created and distributed among companies belonging to industrial clusters in the state of Minas Gerais. The results conclude that, in general, joint procurement in Local Productive Arrangements Miners is very weak and unsystematic.
\end{abstract}

\section{Keywords}

Cooperative purchasing. Group purchasing. Small and medium firms. Business cooperation. Clusters. 